\title{
Improving Teaching and Learning: Students' Perspectives
}

\author{
X. Mara Chen \\ Ellen M. Lawler \\ Elichia A. Venso \\ Salisbury University
}

Despite much debate among educators over methods to improve the climate and effectiveness of teaching and learning, very limited effort has been directed toward seeking input from students. In this study, a survey of students' opinions regarding college teaching and learning was given in six courses with 163 students completing the survey. This chapter analyzed the survey results and proposed specific strategies that professors can use to make teaching engaging as well as informative, and thus, to enbance student learning.

\section{INTRODUCTION}

$A$ majority of educators in a recent California survey claimed critical thinkAing as the primary instructional objective (Elder \& Bartell, 1997; Haas \& Keely, 1998). Understanding of material presented is no longer the only educational objective; college students should be able to apply their knowledge and perform in an ourstanding manner in the real world (Havanek \& Brodwin, 1998; Taylor \& Marienau, 1997). However, college-level education has long focused on providing content instruction rather than promoting learning, and often the present way of teaching does not stimulate active learning (Barr \& Tagg, 1995; Lord, 1994). Teaching has traditionally been practiced as a teacher-centered, teacher-to-learner knowledge transfer process. But today's teaching and learning process has become increasingly complex. The profile of 
student body has become more diverse in terms of experiences, stages of intellectual development, emotional maturity, background, and learning styles. College student diversity calls for effective approaches that take students' learning styles and instructional preferences into account (Cherif, 1994; Nelson, 1996).

Too often, students have been functionally invisible in the classroom (Fabry, Eisenbach, Curry, \& Golich, 1997). The only method used to determine whether a student is engaged intellectually in the classroom is by examination. While more instruction does not necessarily produce and guarantee more learning, effective teaching does promote better learning. There is a growing debate regarding which teaching methods best develop an effective undergraduate learning environment and promote learning excellence. Effective classroom interaction appears to be the key to learning effectiveness. College teaching must appreciate students' preferences in learning environment and teach to their strengths (Cannon, 1997; Krause, 1998). Teaching should no longer be a one-way linear flow, but rather a flexible and interactive process that must engage students at several levels. Hall (1994) points out that we need to be concerned not only about the content we deliver, but also the way in which the learning process takes place.

Many researchers have indicated the need for college teachers to learn about teaching. "Prevailing wisdom is that we teach as we were taught, or if we've given any pedagogical consideration, we teach as we learn. But we must do better than that. We must consider the ways our students need to learn, and teach to their strengths" (Krause, 1998, p. 61). Understanding those differences in which individual students learn will make us more effective teachers. College professors, unlike secondary school teachers, have little formal education and training in teaching methods. Collaborative teaching may provide a good approach to this learning process by sharing experiences and insights (Darling-Hammond, 1998; Quinlan, 1998). Effective instruction should promote students' active involvement in the learning process, and emphasize students' critical thinking and problem solving skills through a provocative inquiry approach (Kronberg \& Griffin, 2000; Mills, 1998; Sternberg, 1998).

Today's workplace demands good analytical and interpersonal skills more than ever, and education should help students develop the skills needed to solve problems effectively as team players, rather than as isolated individuals. Cooperative and collaborative learning and research experiences help students overcome the fear of technical courses while gaining interpersonal skills in teamwork (Metheny \& Metheny, 1997; Nikolova Eddins, Willams, Bushek, Porter, \& Kincke, 1997). What we teach and how we teach are important, but 
what is actually learned by students is more important (Zoller, 2000). College education should incorporate a series of increasingly sophisticated learning processes to foster the development of the students' knowledge pyramid, which consists of a broad conceptual foundation, solid information processing and analytic skills, creative problem solving capabilities, critical thinking, and applied intelligence. Students often engage in learning in response to external pressures (good grades, awards, jobs, etc.). All of these may be valid motivators; however, teachers should add to those motivators and encourage students to get personally and passionately involved in learning for the sake of knowledge and intellectual development (Child \& Williams, 1996).

The above challenges and suggestions from educators have little direct inpur from students. In particular, there have been no opinions sought from students regarding specific measures teachers can take to make teaching and learning more engaging and effective. In this study, we present students' opinions on ways in which instructors can improve teaching and learning effectiveness.

\section{Students' Perspective}

As recipients of information, knowledge, and skills, college students should have a strong voice about the teaching and learning process. Students can present a general framework of teaching effectiveness from the learner's point of view.

Traditionally, student input with regard to teaching consists of end-of-semester teacher and course evaluations, which, while limited, do provide some valuable information. Studies have suggested that students' evaluations of a teacher's overall teaching effectiveness are largely objective and not signifcantly influenced by knowledge of their grades (Baird, 1987; Ikponmwosa, 1986). Tang (1997) found that students' evaluations help to outline the important predicators of an instructor's overall teaching effectiveness. The top four factors outlined in his regression model include informative presentation of subject matter, effective answers to students' questions, a courteous professional manner of treating students, and preparedness for each class.

Our study goes beyond semester evaluations by secking and analyzing students' opinions regarding teaching in general, not just in response to a particular teacher in a specific course. Our different disciplines-geography, biology, and environmental health programs-furthered our interest in gaining a better understanding of students' perspectives about college teaching and learning. 


\section{Survey Design}

The survey questionnaire that we designed and conducted consists of three major sections: student profile, objective questions regarding teaching format, and open-ended questions seeking inpur on desirable attributes of teachers and the classroom environment (Appendix 14.1). Four questions in the student profile section were designed to ensure that the participants are representative of our student body and to identify potential similarities and differences in the responses from the different groups of students to questions relating to the teaching format. The questions in the teaching format section constitute the core of this survey. They are designed to quantify students' preferences regarding teaching styles and format, out-of-classroom activities, the use of technology, and learning responsibility. The last section contains three openended questions designed to seek the students' desired optimum extrinsic factors in their learning. These questions focus on what they perceive as the important qualities of teachers and the classroom environment.

\section{Survey Administration}

The survey was given in the six courses we were teaching at approximately mid-semester in an anonymous and volunteer fashion. We gathered data from students in our courses during class time to ensure independent opinions from each student that were free of other students' influence. Students who were taking two or more courses with us were asked to participate only once. Of the 163 students who participated in the survey, a majority (147) had enrolled in college within two years of their high school graduation. In terms of their class status, 67 were seniors, 45 juniors, and 51 were freshmen and sophomores.

\section{Survey Results and Interpretation}

In processing and analyzing the survey, we have summarized the overall pattern of student opinions, as well as the opinion pattern by student class status, specifically freshmen-sophomore, junior, and senior. The freshmen and sophomore students were combined because few freshmen were enrolled in the majors' classes chosen for the survey. The following important themes were drawn from the responses to the survey's multiple-choice questions (Table 14.1).

Most students (145) prefer a flexible and dynamic lecture format to traditional straight lecturing (see question 5 in Table 14.1). They like lectures that incorporate the suse of visual aids with a moderate amount of classroom discussions and student group work. Only 17 of the students prefer a teacher-centered lecture format, which uses $95 \%$ of the class time for straight lecturing. This 


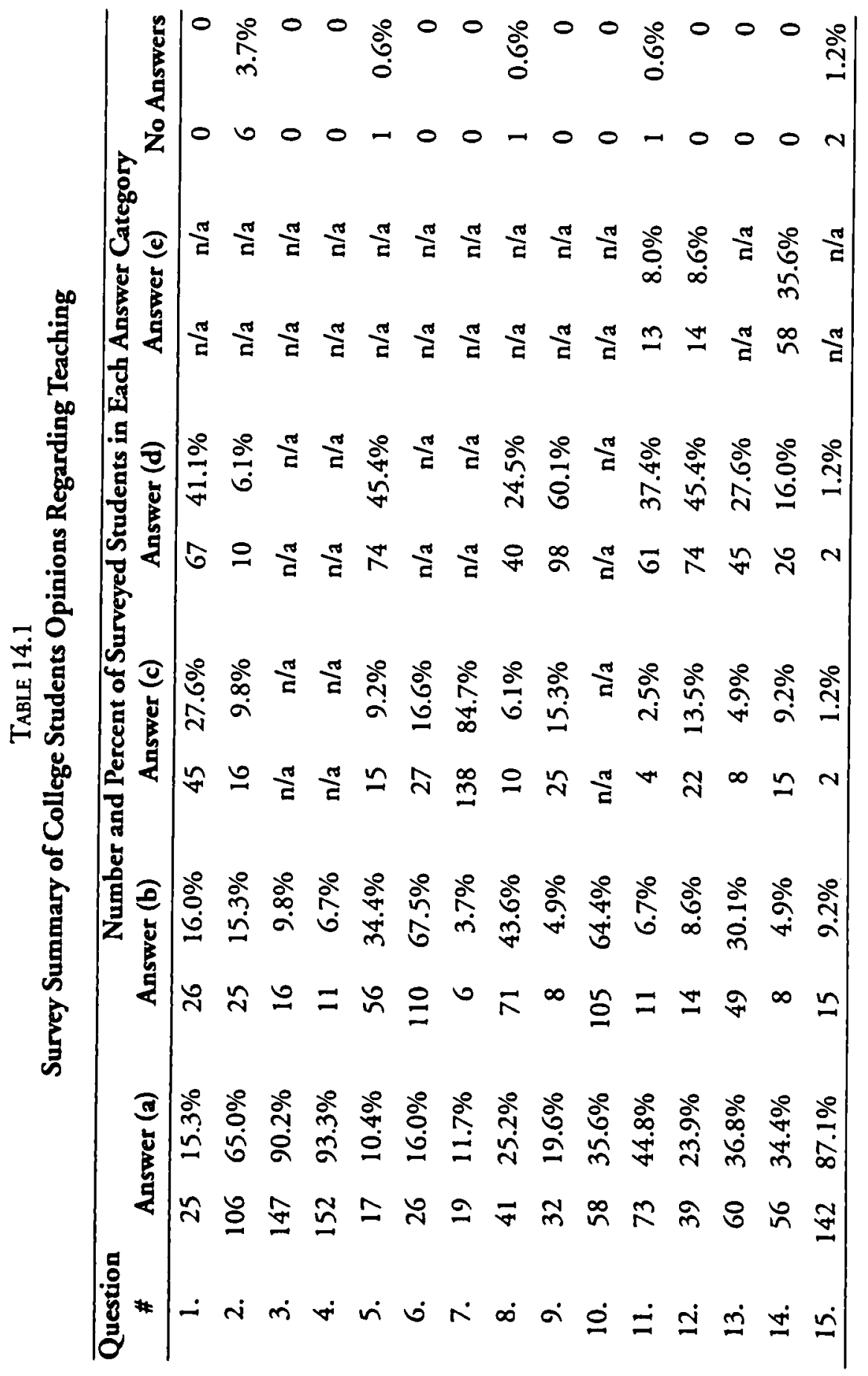


preference suggests that classroom interactions involving more components of the central nervous system promote better learning. Increased sensory input (vision as well as hearing), increased motor output (speaking as well as writing), and increased internal processing (interactive discussions and group work) work together to increase overall learning effectiveness.

The majority of students prefer an instructor who moves about the front of the room and gives an interesting and informative lecture embedded with an occasional pace breaker, such as a joke or a story (110 students answering question 6 and 73 students answering question 11 in Table 14.1). This response indicates that both the content of lecture and method of delivery are important. Instructors can deliver their lectures in a traditional way, in front of the classroom. But they should consciously try to give their presentations with a variety in movement, style, and pace to maintain students' attention and interests.

Most students (98) welcome an inquiry-based teaching approach. They prefer the teacher to ask many questions, and even more important, students want to be encouraged to ask more questions themselves (see question 9 in Table 14.1). In addition, they would like to bave guided and structured group activities to reinforce the lectures. These preferences suggest that college students' critical thinking and teamwork skills need to be fostered and promoted. These higher-level learning skills may not be easily developed from a passive learning environment.

Most of the students surveyed (118) welcome the use of technology beyond the classroom, but a sizable group is still not as enthusiastic as we bave assumed. Contrary to our common perceptions, most students prefer to bave traditional bomework and team projects/reports (see question 13 in Table 14.1). This response, we believe, reflects the students' desire for more feedback than they get from exams or peer electronic discussions about how they are doing in the learning process. In some cases, however, it may reflect some students' desire to have exam grades diluted by graded homework. It is still obviously important for instructors to use their judgment in determining the correct balance of various graded exercises to enhance learning without decreasing course rigor. In addition, the mixed attitude toward the use of technology may also reflect lack of confidence among some students regarding computer technology and highlight the need for activities that produce technologically confident students.

Generally speaking, the students of different class status (senior, junior, soplomore, and freshmen) expressed similar opinions on most of the survey 
questions. Class status did not appear to affect student perceptions of teaching and learning, with the following two exceptions:

- There were striking differences in students' opinion in the desired format of student group work in classroom. Significantly more freshmen and sophomore students preferred structured group discussion than did juniors and seniors, who preferred classes without such group work. This difference may suggest that higher-level students are more mature and ready for more independent learning coupled with direct intellectual exchange in the classroom.

- There were also significant differences in responses regarding learning activities other than group discussion. Most seniors welcome a combination of different learning activities, including homework, presentation, and team projects, while most students from other class status groups prefer homework. This difference may indicate that senior students would like to have the learning opportunities that allow them to sharpen their problem solving and teamwork skills.

Finally, most of our students (142) seemed to bave a mature attitude toward their learning and believed that they themselves bold the ultimate responsibility in achieving a bigh GPA (see question 15 in Table 14.1). Although this attitude may be a comfort to us and is a good beginning, it is still our professional obligation to foster generations of responsible and effective learners.

In addition to multiple-choice questions, our survey contained three open-ended questions designed to identify 1) the common characteristics of instructors perceived as outstanding, 2) the specific things students believe instructors can do to make lectures interesting and informative, and 3) the ideal classroom environment envisioned by students.

Over balf the students surveyed identified similar characteristics as outstanding in both high school and college instructors. Characteristics, such as dedicated, honest, fair, patient, understanding, and reasonable, were cited more frequently than other characteristics, such as knowledgeable, experienced, and organized. Furthermore, a quarter of the students surveyed specifically mentioned the importance of teachers getting to know them as individuals and being accessible outside the classroom. Good communication skills were highly valued, and being interesting was cited almost twice as often as being informative. Being knowledgeable and professionally experienced was cited three times as often as innate intelligence. Students put an increased emphasis on teacher's interpersonal qualities, concerns for students, presentation, and communication skills. 
Instructors can make lectures interesting and engaging, as well as informative, by using visual aids, actively involving students in the classroom, and presenting related personal experiences and anecdotes. Demonstrating the relevance of the course material to the real world was specifically mentioned by over one-third of the respondents. As stated in Lowman's (1996) observational study, exemplary college teachers have a strong power to promote learning by making their courses clear and engaging.

The ideal components of a classroom learning environment include frequent teacher-student interactions, caring and skilled teachers, a small number of students per class, a relaxed atmosphere, and a comfortable, wellequipped classroom. Obviously, students prefer an active learning environment in a well-equipped setting. Although this list does not contain any new revelations, creating such a teaching and learning environment remains challenging.

\section{Discussion on Teaching Strategies}

Achieving educational excellence has called for an integrated curriculum, quality instruction based upon active learning, in- and out-of-class interactions, a stimulating environment with an emphasis on higher expectations, and an understanding and flexible teaching approach for diverse learning styles (Ewell, Jones, \& Lenth, 1996). The results from our study have reinforced these general guiding principles. However, we need to address specific strategies or approaches to fulfill the general educational goals. Based on our survey study, we have come to identify the following specific aspects that can be emphasized to improve the climate and effectiveness of teaching and learning.

- The overall theme of students' responses suggested that teaching-learning interactions that can truly engage the student are critical for effective teaching. Most teachers would probably understand what makes teaching informative, but may not have the concrete ideas about making reaching engaging. Education should focus not only on teaching students what to learn, but also on how to learn (learning to learn). The inquiry-based and student-centered interaction between teacher and students provides students time to process the concepts (Leonard, 2000) and digest the delivered data and information.

- Making teaching interesting does not mean entertaining students. On the contrary, we suggest that we should promote a higher learning standard through a flexible teaching approach, which reduces students' learning stress and improves their learning productivity. As the cognitive content in a course decreases, the teacher should focus more on facilitation rather 
than content delivery (Hall, 1994). Effective teaching requires imagination and creativity in classroom delivery, including the use of humor to reduce anxiety and improve students' ability to learn (Berk, 1996). In addition, Berk (1996) also argues that some of us rarely succeed at anything unless we have fun doing it. We can embed some "fun" things into our teaching to generate and maintain our students' interest and attention in learning, especially in courses that students perceive as boring and difficult. For example, if Fridays appear to be days with a lower attendance, it may help the learning atmosphere to let students have a group discussion on what they have learned during the whole week and/or inject some brief pace breaker stories or a joke into the lectures to stimulate the students. If students see our extra efforts in our teaching, they may be more likely to put extra effort in their learning.

- Active learning results from active teaching. Inquiry-based teaching is suggested to produce a classroom atmosphere marked by intellectual vitality and emotional vigor and promote students' critical thinking (Ahern-Rindell, 1999; Mills, 1998;). Giving students a voice in a course empowers their enthusiasm and improves their attitude about learning (Fabry, Eisenbach, Curry, \& Golich, 1997). Our survey indicates that effective teaching should get students involved by encouraging them to ask/answer more questions in the classroom and by facilitating them to discuss with and learn from their fellow students. However, the survey does not suggest that there is a single best teaching style from which active learning will take place. The effectiveness of teaching in a specific situation is contingent on its relation to students, course content, and learning objectives (Hall, 1994).

- Learning is a dynamic and complex process. The student's intelligence, academic preparedness, mental motivation, emotional desire for knowledge, and maturity for challenge often affect the outcome. Effective learning occurs in a zone of novelty, where students are challenged but not overwhelmed (Sternberg, 1998). Because of this very complexity in learning, effective teaching requires a teacher to play multiple roles in their learning: instructor, facilitator, and mentor in and out of the classroom. Too often, teachers spend much time and effort on content preparation, but too little time and effort on designing and understanding the associated learning process to accomplish teaching objectives. Many of us often play the all-knowing authority figure and believe students lack the potential for a high-level intellectual exchange. This teaching prac- 
tice allows us to recycle our lecture notes, perhaps making our teaching easier, but creating the kind of students we do not respect. Encouraging students to intellectually engage in the classroom creates mutual respect between faculty and students (Giampetro-Meyer, \& Holc, 1997). Only a few students in our survey use words such as "strict," "control," "good disciplinarian," and "complete authority" to describe the characteristics of an outstanding teacher. This may indicate that strict, teacher-centered teaching produces learning apathy. College students welcome freedom and the associated responsibilities in their learning. We must encourage, reward, and guide their engagement in learning, rather than force them to attend classes with an apathetic learning attitude or resentment toward teachers.

- Technology has become a key component in education. Nantz and Lundgren (1998) suggested that the use of technology allows learning across the barriers of time and space by enabling students' access to course materials whenever and wherever they desire. Based on our survey, students welcome the use of videos and computer programs in lecturing, email communication, and the Internet in delivering course materials. However, these same students also stress the importance of an understanding, approachable, and available teacher in their learning. Therefore, the use of technology should be designed and used with care. If the use of email replaces face-to-face interactions, students may have the feeling that the teacher is too busy or does not care enough for them. The use of visual aids, such as videos and the Internet, should be coupled with structured classroom discussion. Otherwise, students certainly enjoy the multimedia show but are unlikely to fully remember or understand what they have seen and heard.

\section{Conclusion}

In light of the results from this survey, it becomes apparent that students perceive the key to effective learning lies in interactive teaching. Teachers should emphasize student-oriented active learning, instead of teacher-centered lecturing. In particular, it is important to provide a stimulating, yet relaxed, learning climate: making instructions engaging, interesting, as well as informative. Effective communication between the teacher and students in and out of the classroom is critical to learning efficiency. The teaching and learning process is analogous to a computer network in which efficient network communications between the server and its node computers becomes impos- 
sible without effective protocols, regardless of the speed and capacity the individual computers might have. In the classroom, a lack of good rapport and mutual respect between teachers and students rarely results in learning excellence, despite well-educated teachers, eager-to-learn students, and wellequipped classrooms.

Although each individual student may not be capable of telling us what we should be doing as effective teachers, students' collective voice can give us a better understanding of their learning process and preferences. From the students' perspective, teachers should encourage them to ask many questions, design more classroom discussions, lecture with the aid of technology, and use occasional pace breakers, such as jokes and stories. In all, effective teaching should focus as much on how to motivate students to learn as on what they should be taught.

\section{REFERENCES}

Ahern-Rindell, A. J. (1999). Apply inquiry-based and cooperative group learning strategies to promote critical thinking. Journal of College Science Teaching, 28 (3), 203-207.

Baird, J. S. (1987). Perceived learning in relation to student evaluation of university instruction. Journal of Educational Psychology, 79(1), 90-91.

Barr, R. B., \& Tagg, J. (1995). From teaching to learning: A new paradigm for undergraduate education. Change, $27(6), 12-25$.

Berk, R. A. (1996). Student rating of 10 strategies for using humor in college teaching. Journal on Excellence in College Teaching. 7(3), 71-92.

Cannon, J. R. (1997). The constructivist learning environment survey may help halt student exodus from college science courses. Journal of College Science Teaching, 27(1), 67-71.

Cherif, A. H. (1994). Instructional strategies that never fail us. Journal of College Science Teaching, 24(1), 55-58.

Child, M., \& Williams, D. D. (1996). College learning and teaching: Struggling with/in the tensions. Studies in Higher Education, 21 (1), 31-45.

Darling-Hammond, L. (1998). Teacher learning that supports student learning. Educational Leadership, 55(5), G-12.

Ewell, P. T., Jones, D. P., \& Lenth, C. S. (1996). What research says about improving undergraduate education: Twelve attributes of good practice. AAHE Bulletin, $5-8$. 
Fabry, V. J., Eisenbach, R., Curry, R. R., \& Golich, V. L. (1997). Thank you for asking: Classroom assessment techniques and students' perceptions of learning. Journal on Excellence in College Teaching, 8(1), 3-21.

Giampetro-Meyer, A., \& Holc, J. (1997). Encouraging students to demonstrate intellectual behavior that professors respect. College Teaching, 45 (3), 92-96.

Haas, P. F., \& Keely, S. M. (1998). Coping with faculty resistance to teaching critical thinking. College Teaching, 46 (2), 63-68.

Hall, F. S. (1994). Management education by design. Journal of Management Education, $18(2), 182-198$.

Havanek, J. E., \& Brodwin, M. G. (1998). Restructuring university and colleges: The student-focused paradigm. Education, 119(1), 115-119.

Ikponmwosa, O. S. H. (1986). Knowledge of grades and student evaluation of university instruction. Indian Journal of Psychometry and Education, 17 (1-2), 47-52.

Krause, L. B. (1998). The cognitive profile model of learning styles. Journal of College Science Teacling. 28(1), 57-61.

Kronberg, J. R., \& Griffin, M. S. (2000). Analysis problems: A means to developing students' critical-thinking skills. Journal of College Science Teaching, 29, 348-352.

Leonard, W. H. (2000). How do college students best learn? An assessment of popular teaching styles and their effectiveness. Journal of College Science Teaching, 29 (6), 385-388.

Lord, T. (1994). Using constructivism to enhance student learning in college biology. Journal of College Science Teaching, 23, 346-348.

Lowman, J. (1996). Characteristics of exemplary teachers. In M. D. Svinicki \& R. J. Menges (Eds.), Honoring exemplary teaching (pp. 33-40). San Francisco, CA: Jossey-Bass.

Metheny, D., \& Metheny, W. (1997). Enriching technical courses with learning teams. College Teaching. 45 (1), 32-36.

Mills, J. (1998). Better teaching through provocation. College Teaching, 46 (1), 21-26.

Nantz, K. S., \& Lundgren, T. D. (1998). Lecturing with technology. College Teaching, 46(2), 53-57.

Nelson, C. E. (1996). Students diversity requires different approaches to college teaching, cven in math and science. American Behavioral Scientist, 40 (2), 165-177. 
Nikolova Eddins, S. G., Willams, D.G., Bushek, D., Porter, D., \& Kineke, G. (1997). Searching for a prominent role of research in undergraduate education: Project interface. Journal on Excellence in College Teaching, 8(1), 69-81.

Paul, R. W., Elder, L., \& Bartell, T. (1997). California teacher preparation for instruction in critical thinking: Research findings and policy recommendations. Sacramento, CA: California Commission on Teacher Credentialing.

Quinlan, K. M. (1998). Promoting faculty learning about collaborative teaching. College Teaching, $46(2), 43-47$.

Sternberg, R. J. (1998). Principles of teaching for successful intelligence. Educational Psychologist, 33, 65-72.

Tang, T. L. (1997). Teaching evaluation at a public institution of higher education: Factors related to the overall teaching effectiveness. Public Personnel Management, $26(3), 379-390$.

Taylor, K., \& Marienau, C. (1997). Constructive development theory as a framework for assessment in higher education. Assessment and Evaluation in Higher Education, 22 (2), 233-244.

Zoller U. (2000). Teaching tomorrow's college science courses: Are we getting it right. Journal of College Science Teaching, 29(6), 409-414. 


\section{Contact:}

X. Mara Chen

Department of Geography and Geosciences

Salisbury University

Salisbury, MD 21801

Voice (410) 546-6202

Fax (410) 548-4506

Email mxchen@salisbury.edu

Ellen M. Lawler, Chair

Department of Biological Sciences

Salisbury University

Salisbury, MD 21801

Voice (410) 543-6496

Fax (410) 543-6433

Email emlawler@salisbury.edu

Elichia A. Venso, Director

Department of Environmental Health Science

Salisbury University

Salisbury, MD 21801

Voice (410) 543-6499

Fax (410) $543-6433$

Email eavenso@salisbury.edu

X. Mara Chen is Associate Professor in the Department of Geography and Geosciences at Salisbury University.

Ellen M. Lawler is Associate Professor in the Department of Biological Sciences at Salisbury University.

Elichia A. Venso is Associate Professor and Director of the Environmental Health Science Program at Salisbury University. 


\section{APPEndix 14.1}

\section{A Survey of Students' Opinions Regarding College Teaching}

For questions 1-4, select the choice that describes your current status and fill in on scantron.

1. Your Classification
(a) Freshman
(b) Sophomore
(c) Junior
(d) Senior

2. Your major is within which school
(a) Henson School of Science and Technology
(b) Fulton School of Liberal Arts
(c) Perdue School of Business
(d) Seidel School of Education and Professional Studies

3. Did you enroll in college within two years of high school graduation?
(a) yes
(b) no

4. You are
(a) full-time
(b) part-time

For questions 5-15, select your TOP PREFERENCE (select ONE only and fill in on scantron).

5. Lecture format
(a) $95 \%$ of time for straight lecturing
(b) lectures supported with visual aids (slides and VCR tapes)
(c) lectures with student discussions/group work
(d) lectures with visual aids, questions/discussions, and student group work

6. Presentation style of instructor
(a) instructor stays at front of room, usually remaining in one area
(b) instructor moves about front of room
(c) instructor moves about room, in amongst students

7. Which is more critical to your classroom learning
(a) a lecture that is interesting
(b) a lecture that is informative
(c) a lecture that is both interesting and informative 
8. Format of student group work in classroom

(a) structured group discussion with given topics

(b) work on solving/answering problems/questions given by instructor

(c) unstructured group discussion (no detailed instructions from the instructor)

(d) I prefer classes without group work

9. Number of questions

(a) Instructor should ask a few questions of students

(b) Instructor should ask many questions of students

(c) Instructor should not ask questions, but encourage students to do so

(d) Instructor should ask many questions and encourage students to do the same

10. Who should ask more questions in classroom?
(a) instructor
(b) students

11. Lecture pace breakers
(a) a story/ joke
(b) a break in lecture to allow for students to have a short discussion
(c) a break to allow students to stretch
(d) combination of above
(e) no pace breaker is necessary

12. Methods for transmission of notes (to supplement traditional use of the blackboard and overheads)
(a) use of instructional technology (videos, computer projections)
(b) use of Internet
(c) use of a course booklet (purchased at university bookstore)
(d) combination of the above
(e) none of the above are necessary

13. Use of technology outside the classroom
(a) course related information available on the web
(b) communications from instructor via email
(c) students required to find related information on the Internet
(d) none of the above 
14. Related activities
(a) homework
(b) student presentations
(c) project report/term paper
(d) team reports/projects
(e) combination of the above

15. For you to achieve a high GPA in your college learning, who plays the most responsible role?
(a) myself
(b) professors
(c) parents
(d) others (specify)

16. List below four characteristics (based on your own experience) that you think make outstanding high school teachers and college professors. High School Teacher
(a)
(b)
(a)
(c)
(b)
(d)
(c)

(d)

College Professor

17. List three major things, which in your opinion professors can do to make lectures interesting as well as informative.
(a)
(b)
(c)

18. On the back of this page, please describe your ideal college classroom learning environment (Please UNDERLINE your key words). 